\title{
Rasta resin-triphenylphosphine oxides and their use as recyclable heterogeneous reagent precursors in halogenation reactions
}

\author{
Xuanshu Xia and Patrick H. Toy*
}

\author{
Letter \\ Address: \\ Department of Chemistry, The University of Hong Kong, Pokfulam \\ Road, Hong Kong, People's Republic of China

\section{Email:} \\ Patrick H. Toy ${ }^{*}$ - phtoy@hku.hk \\ ${ }^{*}$ Corresponding author \\ Keywords: \\ Appel reaction; halogenation; organophosphorus; polymer-supported \\ reagent; rasta resin; triphenylphosphine oxide
}

\section{Open Access}

\author{
Beilstein J. Org. Chem. 2014, 10, 1397-1405. \\ doi:10.3762/bjoc. 10.143 \\ Received: 13 February 2014 \\ Accepted: 18 May 2014 \\ Published: 20 June 2014 \\ This article is part of the Thematic Series "Organophosphorus chemistry". \\ Guest Editor: P. R. Hanson \\ (C) 2014 Xia and Toy; licensee Beilstein-Institut. \\ License and terms: see end of document.
}

\begin{abstract}
Heterogeneous polymer-supported triphenylphosphine oxides based on the rasta resin architecture have been synthesized, and applied as reagent precursors in a wide range of halogenation reactions. The rasta resin-triphenylphosphine oxides were reacted with either oxalyl chloride or oxalyl bromide to form the corresponding halophosphonium salts, and these in turn were reacted with alcohols, aldehydes, aziridines and epoxides to form halogenated products in high yields after simple purification. The polymersupported triphenylphosphine oxides formed as a byproduct during these reactions could be recovered and reused numerous times with no appreciable decrease in reactivity.
\end{abstract}

\section{Introduction}

One of the major drawbacks of the Wittig [1] and Mitsunobu $[2,3]$ reactions is that they result in the formation of a stoichiometric quantity of triphenylphosphine oxide (1) as a byproduct. From an atom economy perspective this is less than ideal, and from an environmental point of view it would be good if $\mathbf{1}$ could be simply reduced to triphenylphosphine (2) for reuse [4]. In this regard Tanaka and co-workers have studied the possibility of applying the reaction first reported by Masaki and Fukui [5] in which 1 can be treated with oxalyl chloride (or bromide) to form halophosphonium salt $\mathbf{3 a}$ (or $\mathbf{3 b}$ ), which in turn can be reduced to 2 under more mild reaction conditions than can 1 (Scheme 1) [6,7].
In addition to being relatively easily reduced, halophosphonium salts $\mathbf{3 a}, \mathbf{b}$ are also useful reagents in a wide range of reactions, such as those illustrated in Scheme 2: (1) the conversion

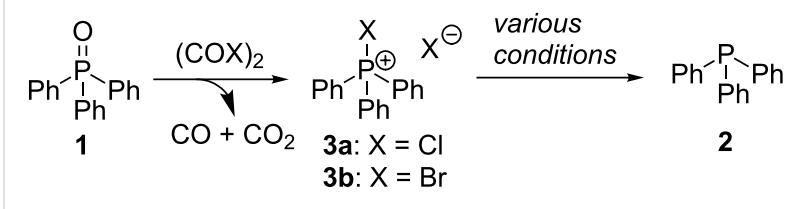

Scheme 1: The Masaki-Fukui reaction and halophosphonium salt reduction. 


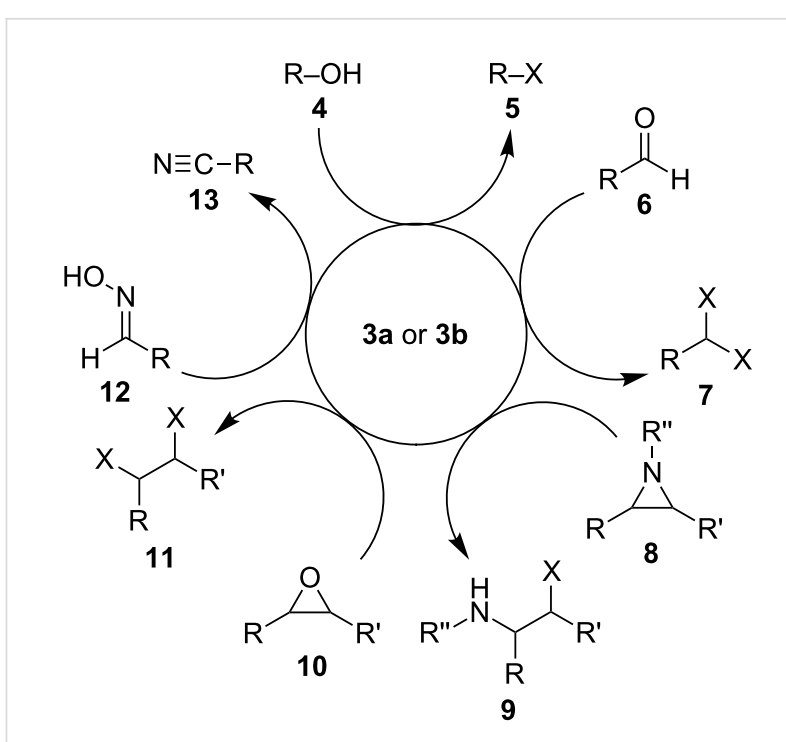

Scheme 2: Representative reactions involving halophosphonium salts 3a,b.

of alcohols 4 to alkyl halides 5 (the Appel reaction), (2) the conversion of aldehydes 6 to 1,1-dihaloalkanes 7, (3) halogenation of aziridines 8 to form 2-haloamines 9, (4) halogenation of epoxides $\mathbf{1 0}$ to form 1,2-dihaloalkanes 11, (5) and the dehydration of oximes $\mathbf{1 2}$ to form nitriles $\mathbf{1 3}$.

Capitalizing on the fact that $\mathbf{1}$ is formed as a byproduct from 3a,b in each of these reactions, Denton and co-workers have recently combined the Masaki-Fukui reaction with many of the functional group transformation outlined in Scheme 2, in onepot processes in which the role of $\mathbf{1}$ is referred to as that of a catalyst [8-12]. For example, catalytic Appel reactions were achieved by slowly adding separate solutions of oxalyl chloride and alcohols 4 to a solution of $\mathbf{1}$ (Scheme 3) [8,9]. In these reactions, the simultaneous slow addition of oxalyl chloride and alcohol substrate $\mathbf{4}$ to a sub-stoichiometric quantity of $\mathbf{3 a}$ was necessary in order to minimize formation of undesired ester side-products formed by the reaction of $\mathbf{4}$ with the acid chloride. Furthermore, chromatographic purification of the alkyl halide product 5 was required. Thus, while the procedures reported by Denton et al. might be conceptually interesting, they may not be particularly convenient to perform, especially on larger scales than what was originally reported.

We have had a long-term interest in the use of organic polymers as supports for reagents and catalysts [13], and have reported the use of various polymer-supported phosphines as reagents, organocatalysts, and ligands in order to simplify product isolation [14-18]. Most recently we have studied the use of the rasta resin polystyrene architecture [19-26] as a platform for reagents and catalysts [27-33], and have used easily synthe-

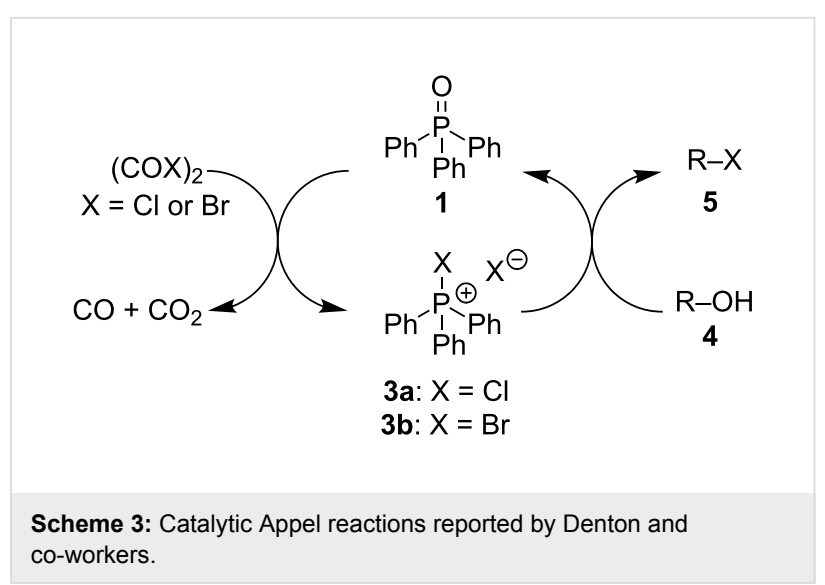

sized rasta resin- $\mathrm{Ph}_{3} \mathrm{P}(\mathbf{1 4})$ in various Wittig reactions that required only filtration and solvent removal for product purification (Figure 1) [27-29]. Additionally, 14 was converted into phosphonium salt 15, which proved to be an efficient and highly recyclable catalyst for aldehyde and ketone cyanosilylation reactions from which the products could also be obtained pure after only filtration and solvent removal [30]. It should be noted that the grafts of the rasta resins reported are random co-polymers, and the structures drawn for them are not mean to indicate that they are block co-polymers. The format for their presentation is used merely to indicate their monomer incorporation ratios.

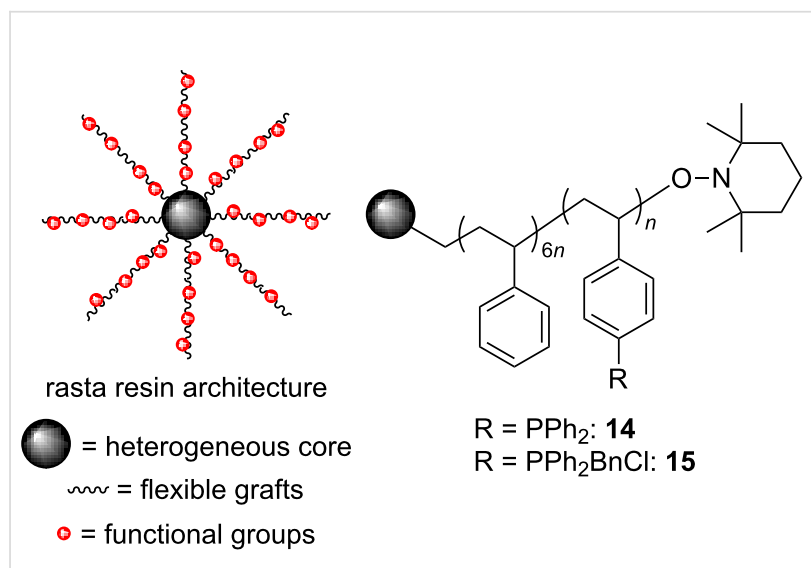

Figure 1: Rasta resins 14 and 15.

Thus, considering our prior success in using 14 and 15 , we wanted to oxidize 14 to $\mathbf{1 6}$, and in turn use this as a heterogeneous precursor to reagents $\mathbf{1 7 a}, \mathbf{b}$ for use in the halogenation reactions described in Scheme 2. We anticipated that using a full equivalent $\mathbf{1 7} \mathbf{a}, \mathbf{b}$ generated in situ would eliminate the need for slow addition of the oxalyl halide to form the halophosphonium salt, and thus allow for the reactions to be performed more conveniently than in the catalytic procedures of Denton and 
co-workers. Furthermore, since $\mathbf{1 6}$ would be the byproduct of the reactions, it could be recovered by filtration at the end of the reactions and reused directly. Herein we report the realization of this strategy and describe simple procedures for alcohol, aziridine, aldehyde and epoxide halogenation reactions from which the desired products are easily isolated and the phosphine oxide byproduct is readily recycled.

\section{Results and Discussion}

Rasta resin 16 was prepared by oxidation of $\mathbf{1 4}$, which was prepared as previously reported [28], using $\mathrm{H}_{2} \mathrm{O}_{2}$ (Scheme 4). The loading level of $\mathbf{1 6}$ was determined by elemental analysis to be $0.97 \mathrm{mmol} / \mathrm{g}$, and gel-phase ${ }^{31} \mathrm{P}$ NMR spectroscopic analysis of $\mathbf{1 6}$ showed only a single peak at $29.4 \mathrm{ppm}$, indicating that the phosphine groups were completely oxidized.

\section{Appel reactions using 16}

With 16 in hand, we initially used it to perform Appel reactions by first converting it into either $\mathbf{1 7} \mathbf{a}$ or $\mathbf{1 7} \mathbf{b}$ in situ (Scheme 4). To do this, 16 was suspended/swollen in dichloromethane, and then the appropriate oxalyl halide was added. Once gas evolution ceased, alcohol $\mathbf{4}$ was added, and the reaction mixture was heated to reflux. Progress of the reactions was monitored by
TLC analysis, and they were all finished in 4-7 hours. Upon completion, the reaction mixtures were cooled to room temperature and then filtered. Finally, the filtrates were concentrated at reduced pressure to afford the desired products that were essentially pure based on ${ }^{1} \mathrm{H}$ and ${ }^{13} \mathrm{C}$ NMR spectroscopic analyses. Chromatographic purification of the resultant alkyl halide products was not required. As can be seen in Table 1, both primary (entries 1-8) and secondary (entries 9 and 10) benzylic alcohols with various substituents all afforded excellent yield of the corresponding chloride and bromide using this procedure. Similar high yields were also obtained from reactions using primary (Table 1, entries 11-14) and secondary aliphatic alcohols (Table 1, entries 15 and 16). A reaction performed on a scale ten times larger afforded excellent yield as well (Table 1, entry 17). The recovered polymer was washed sequentially with water, $\mathrm{MeOH}, \mathrm{THF}$, diethyl ether and hexane. After drying, ${ }^{31} \mathrm{P}$ NMR spectroscopy confirmed its identity as $\mathbf{1 6 .}$

\section{Aldehyde halogenation reactions using 16}

With the success of the Appel reactions, we further examined the utility of $\mathbf{1 6}$ by studying its use in aldehyde halogenation reactions. As before, 16 was converted into $17 \mathbf{a}$ or $\mathbf{1 7 b}$ in situ, and aldehyde $\mathbf{6}$ was added upon cessation of gas evolution.<smiles>CC1(C)CCCC(C)(C)N1OC(CC(CCCO)c1ccccc1)c1ccc(P(=O)(O)c2ccccc2)cc1</smiles>

16

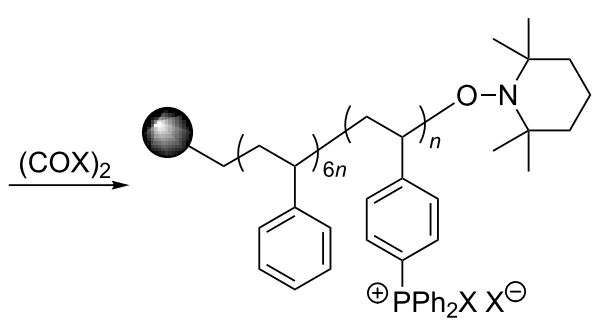

17a: $\mathrm{X}=\mathrm{Cl}$

$17 \mathrm{~b}: \mathrm{X}=\mathrm{Br}$

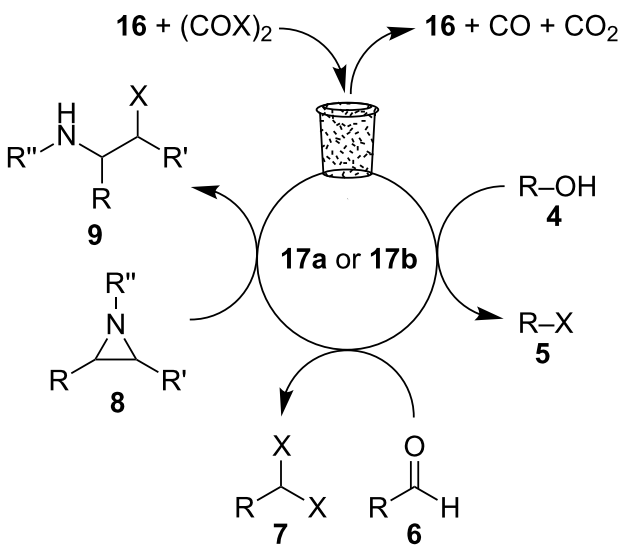


Table 1: Appel reactions using $16 .^{a}$

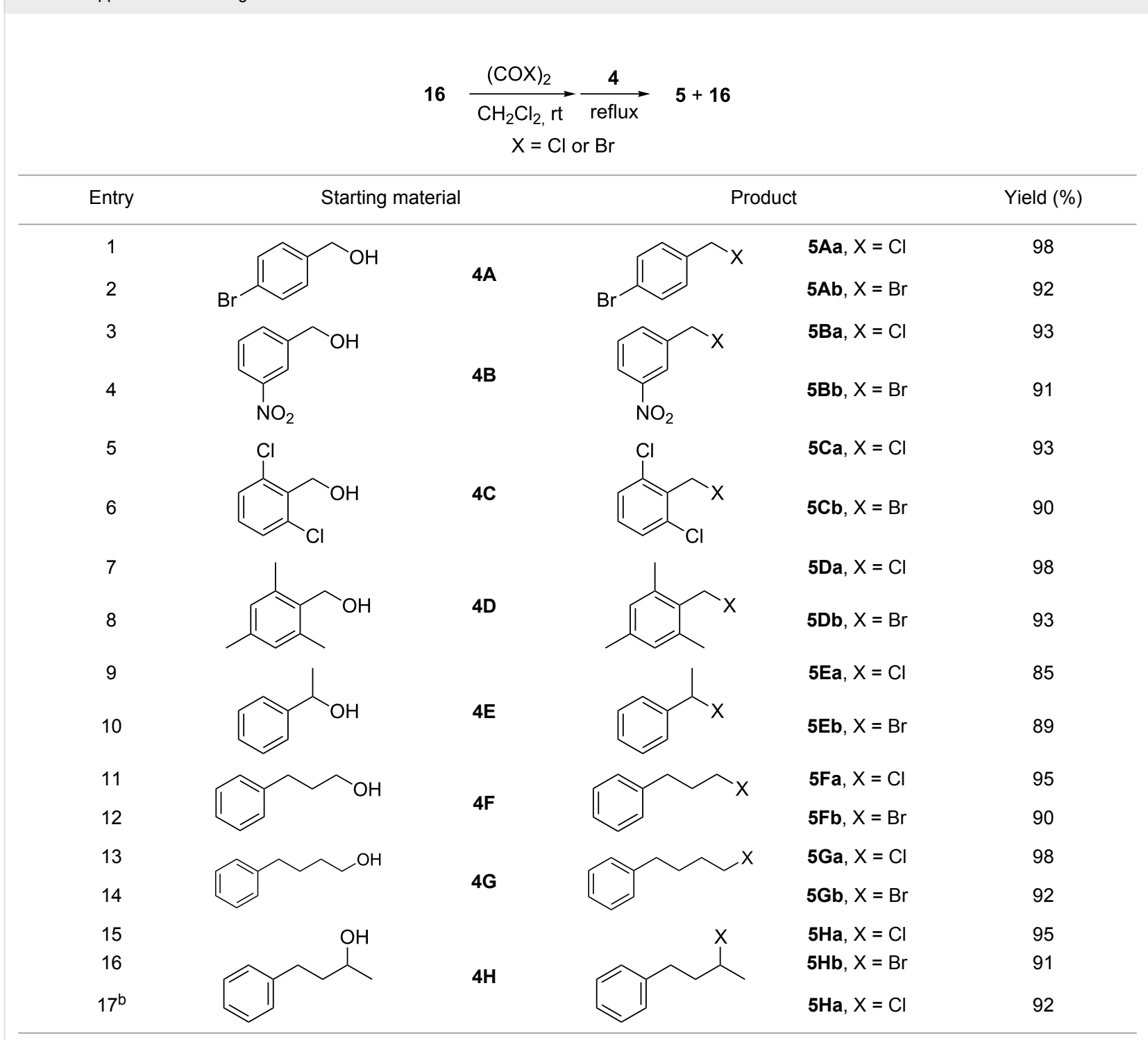

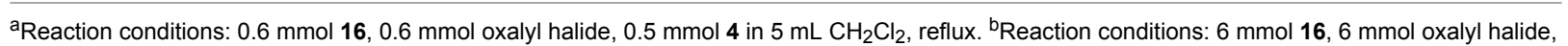
$5 \mathrm{mmol} 4$ in $50 \mathrm{~mL} \mathrm{CH}_{2} \mathrm{Cl}_{2}$, reflux.

After 72 hours at reflux, the reactions were stopped, filtered and the products were purified by column chromatography (Table 2). Unlike the Appel reactions discussed above, some of these reactions did not proceed to completion, even when the reaction time was lengthened. Generally, it was observed that the bromination reactions afforded higher product yields than did the corresponding chlorination reactions (Table 2, entries 1-8), except when electron-rich aldehyde starting materials were used (Table 2, entries 9-12). These results are generally similar to what was previously reported by Denton and co-workers when similar substrates were used [12].

\section{Aziridine halogenation reactions using 16}

We next examined the use of $\mathbf{1 6}$ as a precursor to $\mathbf{1 7 a}$ and $\mathbf{1 7 b}$ in aziridine halogenation reactions [34]. Using reaction conditions similar to those used for the Appel and aldehyde halogenation reactions, a variety of $N$-tosyl aziridines 8 were successfully converted into the corresponding chloro- or bromotosylamides 9 in excellent yields (Table 3 ). The trans configurations of the $9 \mathbf{B a}$ and $\mathbf{9 B b}$ were confirmed by X-ray diffraction analysis of the isolated products, and as was true for the Appel reactions described above, all the products were obtained in high purity simply by filtration to remove the polymer, and 
Table 2: Halogenation reactions of aldehydes using $16 .^{a}$

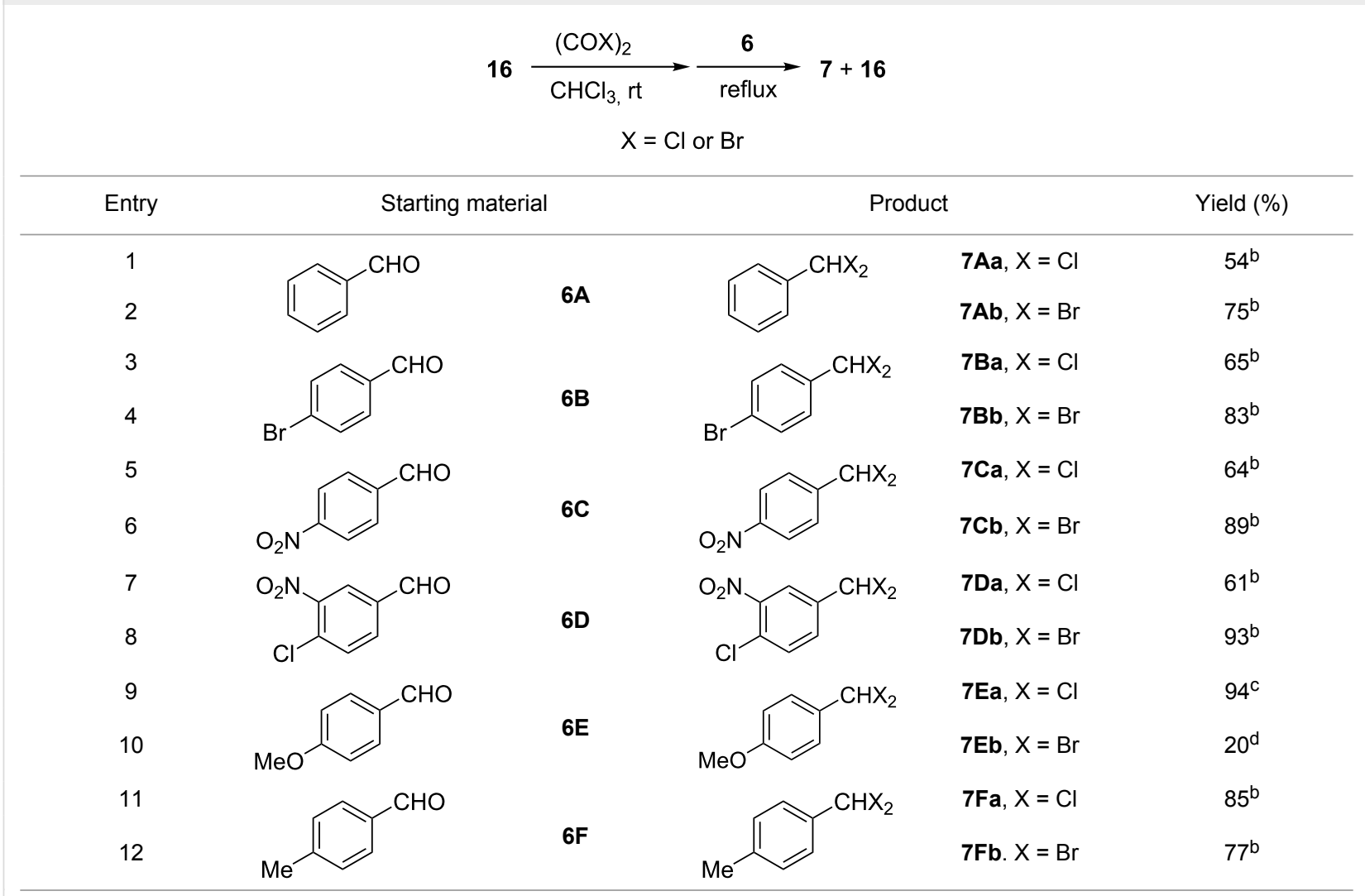

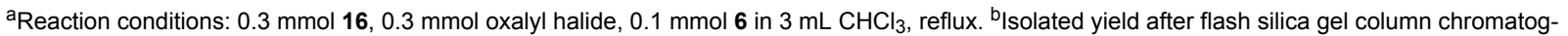
raphy. ${ }^{C}$ Isolated yield after filtration and concentration under reduced pressure. ${ }^{d}$ Determined by ${ }^{1} \mathrm{H}$ NMR spectroscopy.

concentration of the filtrate. Our procedure was also successfully performed on a gram-scale (Table 3, entry 5), and substrates 8 possessing a single aryl substituent were halogenated as the less hindered position (Table 3, entries 10-13).

\section{Recovery and reuse of 16}

After demonstrating that $\mathbf{1 6}$ could effectively serve as a precursor to $\mathbf{1 7 a}, \mathbf{b}$, and realizing that it was returned as the byproduct of the above reactions, we next examined its recyclability in the chlorination of alcohol $\mathbf{4 H}$ and aziridine $\mathbf{8 B}$ The results of these studies are shown in Table 4 and Table 5, respectively. In these experiments, the polymer recovered by filtration of the reaction mixture was washed and dried, and then used directly for the next reaction cycle. Excellent yields were successfully obtained for 8 runs with both $\mathbf{4 H}$ and $\mathbf{8 B}$. Gel-phase ${ }^{31} \mathrm{P}$ NMR analysis of $\mathbf{1 6}$ recovered at the end of these experiments indicated no change in its oxidation state.

\section{Epoxide halogenation reactions}

With the versatility and excellent reactivity of $\mathbf{1 6}$ established, we were encouraged to examine our method in the epoxide halogenation reactions shown in Scheme 2. Since these reactions require the use of a base, we designed a bifunctional rasta resin, RR-NBniPr $2-\mathrm{PPh}_{3}=\mathrm{O} 18$ (Scheme 5), which bears both triphenylphosphine oxide and tertiary amine moieties, in order to increase the efficiency and appeal of our method. We have extensive experience in preparing functionalized resins with two different catalytic groups [35-38], and prepared 18 by oxidation of 19, which we previously used as a bifunctional reagent in one-pot Wittig reactions [29]. Gel-phase ${ }^{31} \mathrm{P}$ NMR spectroscopic analysis of $\mathbf{1 8}$ indicated that oxidation of the phosphine groups was complete, and elemental analysis was used to determine the loading level of phosphine oxide and amine groups to be $1.07 \mathrm{mmol} / \mathrm{g}$ and $1.06 \mathrm{mmol} / \mathrm{g}$, respectively. It should be noted that a test reaction between $N, N$-diisopropylbenzylamine and $\mathrm{H}_{2} \mathrm{O}_{2}$ under similar reaction conditions does not result in amine oxidation, and this seems to indicate that only the phosphine groups of $\mathbf{1 9}$ are oxidized during its conversion to $\mathbf{1 8}$

Having successfully synthesized polymer 18, we examined its reactivity in epoxide halogenation reactions (Table 6). As 
Table 3: Halogenation reactions of aziridines using 16 . $^{\text {a }}$

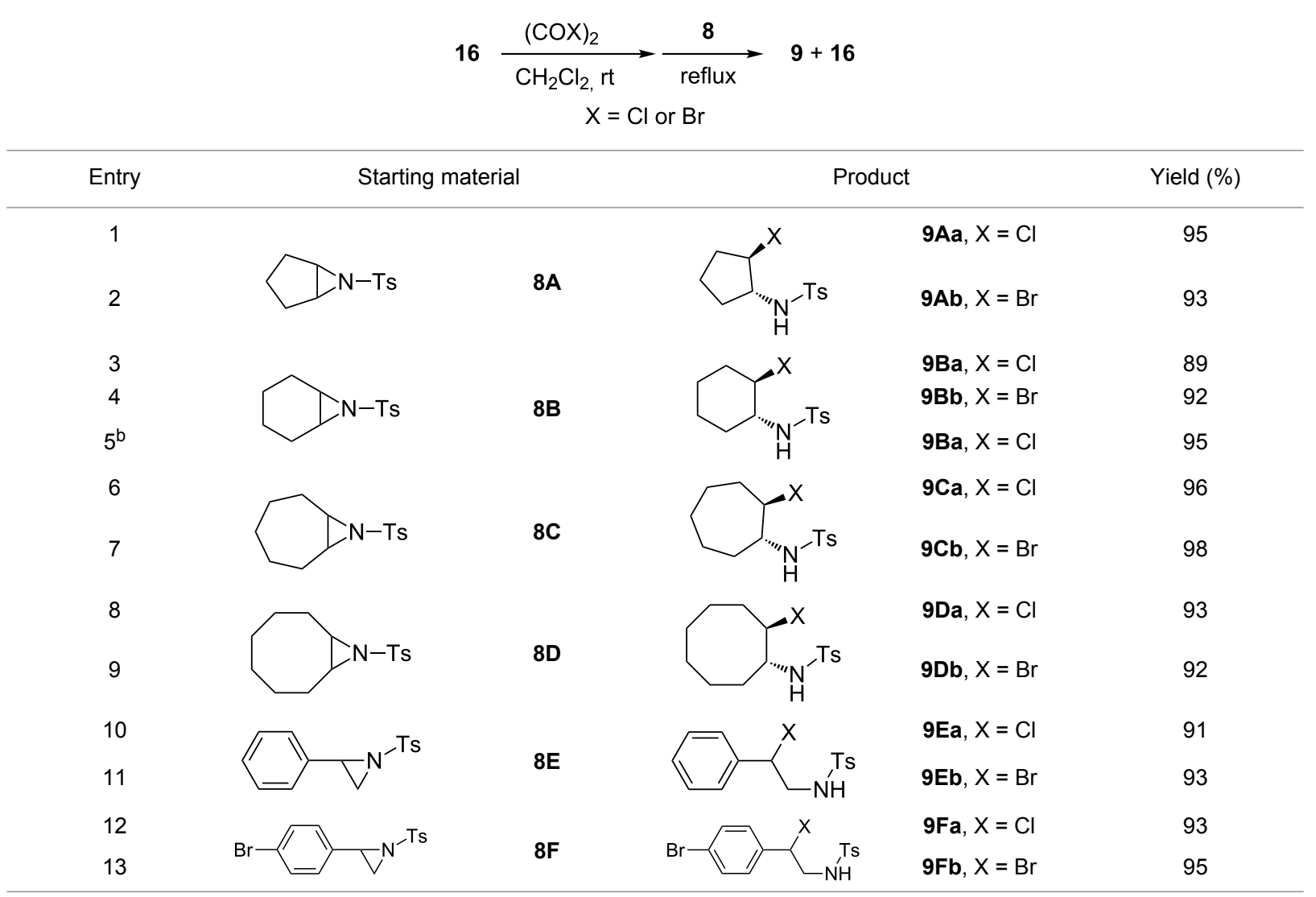

aReaction conditions: $0.6 \mathrm{mmol}$ 16, $0.6 \mathrm{mmol}$ oxalyl halide, $0.5 \mathrm{mmol} 8 \mathrm{in} 5 \mathrm{~mL} \mathrm{CH}_{2} \mathrm{Cl}_{2}$, reflux. ${ }^{b}$ Reaction conditions: $6 \mathrm{mmol}$ 16, $6 \mathrm{mmol}$ oxalyl halide, $5 \mathrm{mmol} 8$ in $50 \mathrm{~mL} \mathrm{CH} \mathrm{Cl}_{2}$, reflux.

Table 4: Recycling of 16 in the chlorination of $4 \mathrm{H}^{\mathrm{a}}$

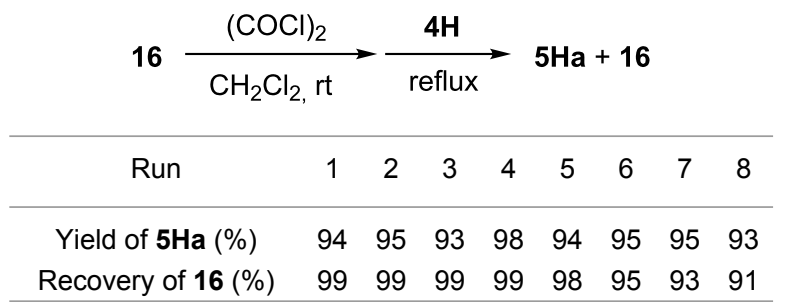

aReaction conditions: $0.6 \mathrm{mmol} 16,0.6 \mathrm{mmol}$ oxalyl chloride, $0.5 \mathrm{mmol}$ $4 \mathrm{H}$ in $5 \mathrm{~mL} \mathrm{CH} \mathrm{Cl}_{2}$, reflux.

before, $\mathbf{1 8}$ was suspended/swollen in solvent prior to addition of the oxalyl halide. Once gas evolution ceased, epoxide $\mathbf{1 0}$ was added, and the reaction mixture was heated to reflux. When TLC analysis indicated that the reactions were complete, 3-4 hours, the reaction mixtures were filtered and the filtrates were concentrated to afford products that were essentially pure according to both ${ }^{1} \mathrm{H}$ and ${ }^{13} \mathrm{C}$ NMR analysis. Reactions with
Table 5: Recycling of 16 in the chlorination of 8B. ${ }^{a}$

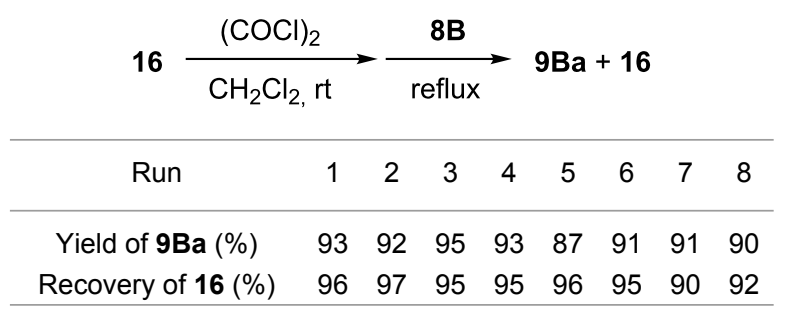

aReaction conditions: $0.6 \mathrm{mmol} 16,0.6 \mathrm{mmol}$ oxalyl chloride, $0.5 \mathrm{mmol}$ $8 \mathrm{~B}$ in $5 \mathrm{~mL} \mathrm{CH}_{2} \mathrm{Cl}_{2}$, reflux.

epoxides bearing phenyl (Table 6, entries 1 and 2), benzyl (Table 6, entries 3 and 4), and alkyl substutients (Table 6, entries 5-8) all proceeded to completion, and afforded the corresponding 1,2-dihalides in excellent yields.

We also examined the recyclability of $\mathbf{1 8}$ in the halogenation of epoxide 10C (Table 7). As was the case for 16, bifunctional 
Table 6: Halogenation reactions of epoxides using $18 .^{a}$

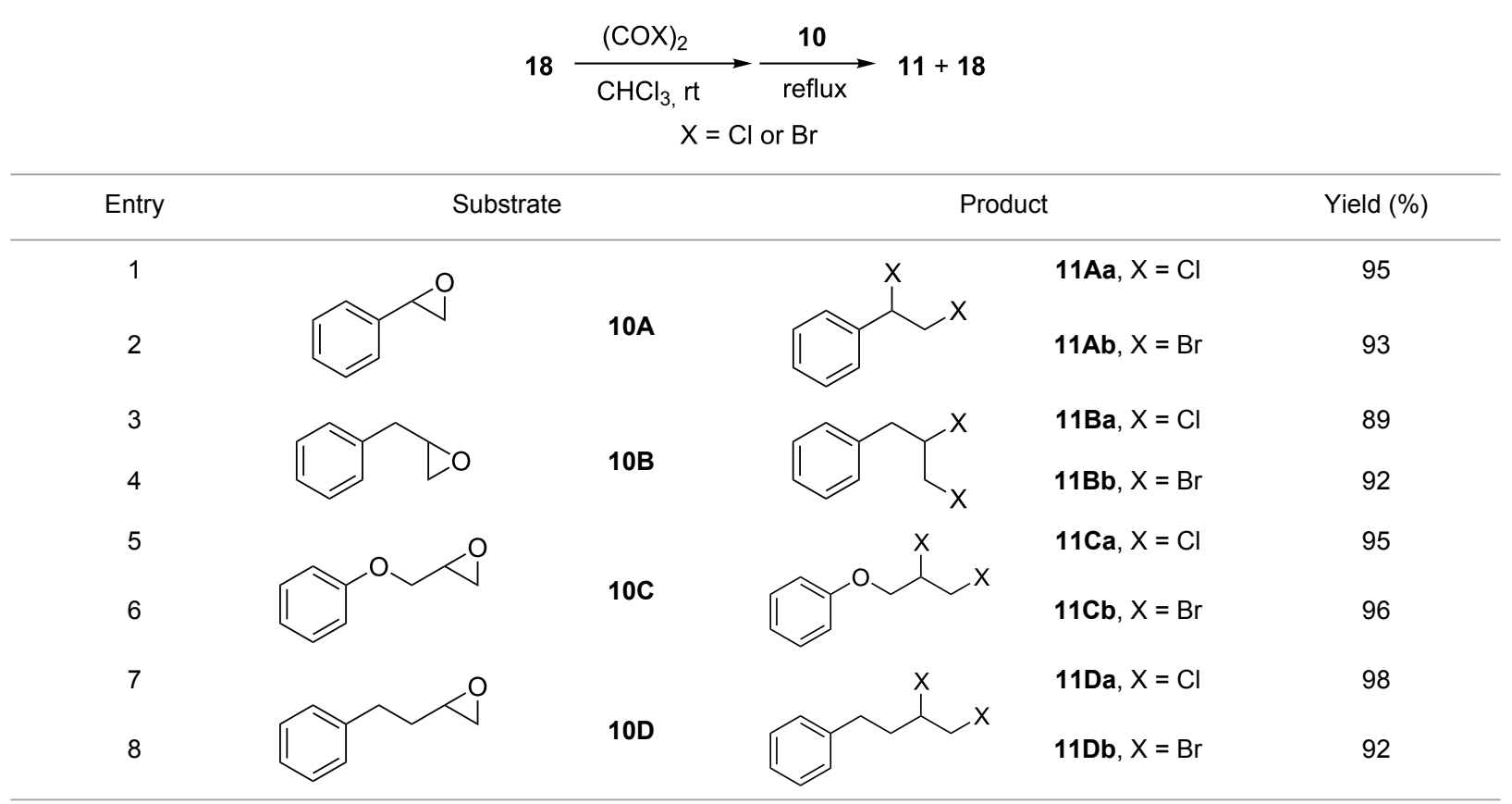

aReaction conditions: $1.2 \mathrm{mmol} 18,1.1 \mathrm{mmol}$ oxalyl halide, $0.5 \mathrm{mmol} 10 \mathrm{in} 5 \mathrm{~mL} \mathrm{CHCl}$, reflux.

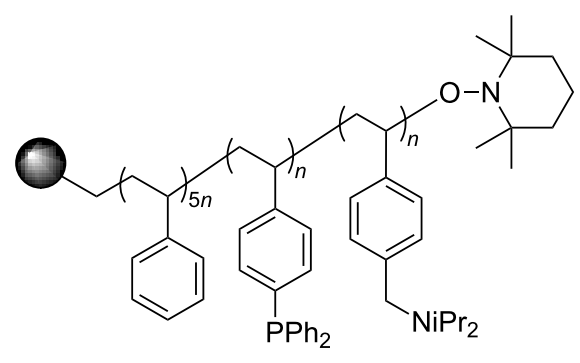

19

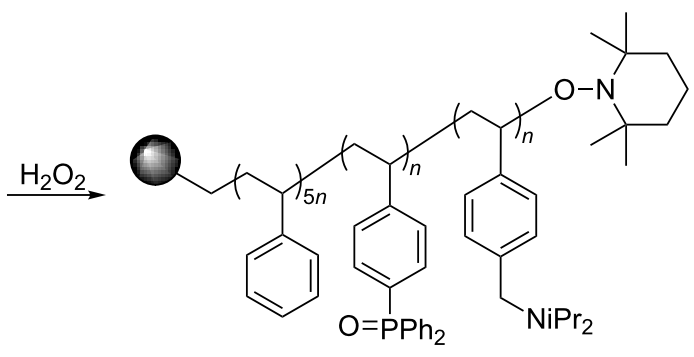

18

Scheme 5: Synthesis of bifuncitonal rasta resin 18.

polymer 18 could be repeatedly recovered and reused without an observable decrease in its reactivity. However, whereas $\mathbf{1 6}$ could be reused directly after recover, reusing 18 required washing it with an aqueous solution of $\mathrm{Na}_{2} \mathrm{CO}_{3}$ after each reaction.

\section{Conclusion}

In summary, we have designed and synthesized recyclable heterogeneous rasta resin-supported triphenylphosphine oxide 16, and have applied it as a phosphonium halide salt precursor in a wide range of halogenation reactions from which it is readily recovered and reused. The reusability of this polymer
Table 7: Recycling of 18 in the chlorination of $10 c^{a}$

$$
18 \underset{\mathrm{CHCl}_{3}, \mathrm{rt}}{\stackrel{(\mathrm{COCl})_{2}}{\longrightarrow}} \underset{\text { reflux }}{\stackrel{10 \mathrm{C}}{\longrightarrow}} 11 \mathrm{Ca}+18
$$

Run

$\begin{array}{lllllll}1 & 2 & 3 & 4 & 5 & 6 & 7\end{array}$

Yield of 11Ca (\%) $\quad 94 \quad 91 \quad 93 \quad 94 \quad 93 \quad 92 \quad 90$

Recovery of $18(\%) \quad 98 \quad 98 \quad 97 \quad 98 \quad 95 \quad 93 \quad 90$

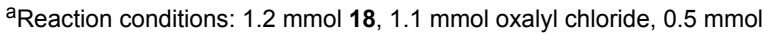
$10 \mathrm{C}$ in $5 \mathrm{~mL} \mathrm{CHCl}_{3}$, reflux. 
was demonstrated by the fact that all of the reactions reported herein involving 16 were performed by repeatedly reusing a single batch of it. We also prepared bifunctional rasta resin $\mathbf{1 8}$ which bears amine groups in addition to the phosphine oxide moieties for use in epoxide halogenation reactions. The products of all of these reactions, except for the aldehyde halogenation reactions, can be easily separated from the phosphine oxide functionalized polymer simply by filtration, and isolated directly in high purity. Thus, the use of polymers $\mathbf{1 6}$ or $\mathbf{1 8}$ as reagent precursors represents a convenient alternative to the "phosphine oxide-catalyzed" methods of Denton and co-workers, which generally require slow addition of the oxalyl halide and chromatographic purification of the product. In order to assess the overall utility of $\mathbf{1 6}$ and $\mathbf{1 8}$, we are currently examining their applications as organocatalysts [39-43], and will report results of these studies in due course.

\section{Experimental}

General procedure for Appel reactions using 16: Polymer 16 $(0.6 \mathrm{~g}, 0.6 \mathrm{mmol})$ was suspended in dichloromethane $(5 \mathrm{~mL})$, and the oxalyl halide $(0.6 \mathrm{mmol})$ was added. Upon cessation of gas evolution, alcohol 4 (0.5 mmol) was added, and the reaction mixture magnetically stirred and heated to reflux. After the reaction was completed as monitored by TLC, the mixture was cooled to room temperature and filtered. The solid on funnel was washed with dichloromethane $(10 \mathrm{~mL} \times 3)$. The solvent of filtrate was removed under reduced pressure to afford the desired product 5 in an essentially pure state based on ${ }^{1} \mathrm{H}$ and ${ }^{13} \mathrm{C}$ NMR spectroscopic analyses.

\section{General procedure for aldehyde halogenation reactions} using 16: Polymer 16 (0.3 g, $0.3 \mathrm{mmol})$ was suspended in chloroform $(3 \mathrm{~mL})$, and the oxalyl halide was added $(0.3 \mathrm{mmol})$. Upon cessation of gas evolution, aldehyde $6(0.1 \mathrm{mmol})$ was added, and the reaction mixture was magnetically stirred and heated to reflux. After 72 hours, the reaction was cooled to room temperature and filtered. The solid on funnel was washed with dichloromethane $(5 \mathrm{~mL} \times 3)$. The solvent of filtrate was removed under reduced pressure. The resulting crude product 7 was purified by flash silica gel column chromatography using ethyl acetate and hexane as eluent mixture.

\section{General procedure for aziridine halogenation reactions of} using 16: Polymer 16 (0.6 g, $0.6 \mathrm{mmol})$ was suspended in dichloromethane $(5 \mathrm{~mL})$, and the oxalyl halide was added $(0.6 \mathrm{mmol})$. Upon cessation of gas evolution, aziridine $\mathbf{8}$ $(0.5 \mathrm{mmol})$ was added, and the reaction mixture was magnetically stirred and heated to reflux. After the reaction was completed as monitored by TLC, the mixture was cooled to room temperature and filtered. The solid on funnel was washed with dichloromethane $(10 \mathrm{~mL} \times 3)$. The solvent of filtrate was removed under reduced pressure to afford the desired product 9 in an essentially pure state based on ${ }^{1} \mathrm{H}$ and ${ }^{13} \mathrm{C}$ NMR spectroscopic analyses.

\section{General procedure for epoxide halogenation reactions using} 18: Polymer 18 (1.3 g, $1.2 \mathrm{mmol}$ ) was suspended in chloroform $(10 \mathrm{~mL})$ and the oxalyl halide was added $(1.1 \mathrm{mmol})$. Upon cessation of gas evolution, epoxide $\mathbf{1 0}(0.5 \mathrm{mmol})$ was added, and the reaction was magnetically stirred and heated to reflux. After the reaction was completed as monitored by TLC, the mixture was cooled to room temperature and filtered. The solid on funnel was washed with dichloromethane $(10 \mathrm{~mL} \times 3)$. The solvent of filtrate was removed under reduced pressure to afford the desired product $\mathbf{1 1}$ in an essentially pure state based on ${ }^{1} \mathrm{H}$ and ${ }^{13} \mathrm{C}$ NMR spectroscopic analyses.

General procedure for recovery and reuse of 16 and 18: After being separated from the reaction mixture by filtration, the polymer, $\mathbf{1 6}$ or $\mathbf{1 8}$, was rinsed sequentially using deionized water $(30 \mathrm{~mL})$, dichloromethane $(50 \mathrm{~mL}), \mathrm{MeOH}(50 \mathrm{~mL})$, THF $(50 \mathrm{~mL})$, diethyl ether $(50 \mathrm{~mL})$, hexane $(50 \mathrm{~mL})$. It was then dried under vacuum at $60{ }^{\circ} \mathrm{C}$ prior to use in the next reaction cycle. Furthermore, $\mathbf{1 8}$ was initially washed with a saturated aqueous solution of $\mathrm{Na}_{2} \mathrm{CO}_{3}$ in order to ensure that it was deprotonated and ready for use in the next reaction cycle.

\section{Note Added in Proof}

After the initial submission of our manuscript we became aware of a recent report by Denton and co-workers regarding similar work using polystyrene-supported halophosphonium salts in Appel and dehydration reactions [44]. This work utilized a commercially available polymer-supported phosphine oxide based on the Merrifield resin architecture, and it is noteworthy that the reactions reported in this manuscript required a 6 -fold excess of the halophosphonium salt compared to the substrate. Use of our rasta resins $\mathbf{1 6}$ and $\mathbf{1 8}$ required only a $20 \mathrm{~mol} \%$ excess.

\section{Supporting Information}

\section{Supporting Information File 1}

Additional experimental details and characterization data of synthesized compounds.

[http://www.beilstein-journals.org/bjoc/content/ supplementary/1860-5397-10-143-S1.pdf]

\section{Acknowledgements}

This research was supported financially by the University of Hong Kong and the Research Grants Council of the Hong Kong S. A. R., P. R. of China (Project No. HKU 705209P). 


\section{References}

1. Wittig, G.; Geissler, G. Liebigs Ann. Chem. 1953, 580, 44-57. doi:10.1002/jlac.19535800107

2. Mitsunobu, O.; Yamada, M. Bull. Chem. Soc. Jpn. 1967, 40, 2380-2382. doi:10.1246/bcsj.40.2380

3. But, T. Y. S.; Toy, P. H. Chem.-Asian J. 2007, 2, 1340-1355. doi:10.1002/asia.200700182

4. Constable, D. J. C.; Dunn, P. J.; Hayler, J. D.; Humphrey, G. R.; Leazer, J. J. L.; Linderman, R. J.; Lorenz, K.; Manley, J. Pearlman, B. A.; Wells, A.; Zaks, A.; Zhang, T. Y. Green Chem. 2007, 9, 411-420. doi:10.1039/b703488c

5. Masaki, M.; Fukui, K. Chem. Lett. 1977, 151-152. doi:10.1246/cl.1977.151

6. Yano, T.; Hoshino, M.; Kuroboshi, M.; Tanaka, H. Synlett 2010, 801-803. doi:10.1055/s-0029-1219194

7. Yano, T.; Kuroboshi, M.; Tanaka, H. Tetrahedron Lett. 2010, 51, 698-701. doi:10.1016/j.tetlet.2009.11.115

8. Denton, R. M.; An, J.; Adeniran, B. Chem. Commun. 2010, 46, 3025-3027. doi:10.1039/C002825H

9. Denton, R. M.; An, J.; Adeniran, B.; Blake, A. J.; Lewis, W.; Poulton, A. M. J. Org. Chem. 2011, 76, 6749-6767. doi:10.1021/jo201085r

10. Denton, R. M.; Tang, X. P.; Przeslak, A. Org. Lett. 2010, 12, 4678-4681. doi:10.1021/ol102010h

11. Denton, R. M.; An, J.; Lindovska, P.; Lewis, W. Tetrahedron 2012, 68, 2899-2905. doi:10.1016/j.tet.2012.01.067

12. An, J.; Tang, X. P.; Moore, J.; Lewis, W.; Denton, R. M. Tetrahedron 2013, 69, 8769-8776. doi:10.1016/j.tet.2013.07.100

13. Lu, J.; Toy, P. H. Chem. Rev. 2009, 109, 815-838. doi:10.1021/cr8004444

14. Choi, M. K. W.; He, H. S.; Toy, P. H. J. Org. Chem. 2003, 68, 9831-9834. doi:10.1021/jo035226+

15. Zhao, L.-J.; He, H. S.; Shi, M.; Toy, P. H. J. Comb. Chem. 2004, 6, 680-683. doi:10.1021/cc049917a

16. Harned, A. M.; He, H. S.; Toy, P. H.; Flynn, D. L.; Hanson, P. R. J. Am. Chem. Soc. 2005, 127, 52-53. doi:10.1021/ja045188r

17. Zhao, L.-J.; Kwong, C. K.-W.; Shi, M.; Toy, P. H. Tetrahedron 2005, 62, 12026-12032. doi:10.1016/j.tet.2005.05.108

18. He, H. S.; Yan, J. J.; Shen, R.; Zhuo, S.; Toy, P. H. Synlett 2006, 563-566. doi:10.1055/s-2006-933128

19. Hodges, J. C.; Harikrishnan, L. S.; Ault-Justus, S. J. Comb. Chem. 2000, 2, 80-88. doi:10.1021/cc990067m

20. Lindsley, C. W.; Hodges, J. C.; Filzen, G. F.; Watson, B. M.; Geyer, A. G. J. Comb. Chem. 2000, 2, 550-559. doi:10.1021/cc000037f

21. McAlpine, S. R.; Lindsley, C. W.; Hodges, J. C.; Leonard, D. M.; Filzen, G. F. J. Comb. Chem. 2001, 3, 1-5. doi:10.1021/cc000068a

22. Wisnoski, D. D.; Leister, W. H.; Strauss, K. A.; Zhao, Z.; Lindsley, C. W. Tetrahedron Lett. 2003, 44, 4321-4325. doi:10.1016/S0040-4039(03)00951-1

23. Fournier, D.; Pascual, S.; Montembault, V.; Haddleton, D. M.; Fontaine, L. J. Comb. Chem. 2006, 8, 522-530. doi:10.1021/cc0600122

24. Fournier, D.; Pascual, S.; Montembault, V.; Fontaine, L. J. Polym. Sci., Part A: Polym. Chem. 2006, 44, 5316-5328. doi:10.1002/pola.21644

25. Pawluczyk, J. M.; McClain, R. T.; Denicola, C.; Mulhearn, J. J.; Rudd, D. J.; Lindsley, C. W. Tetrahedron Lett. 2007, 48, 1497-1501. doi:10.1016/j.tetlet.2006.12.040
26. Chen, G.; Tao, L.; Mantovani, G.; Geng, J.; Nystroem, D.; Haddleton, D. M. Macromolecules 2007, 40, 7513-7520. doi:10.1021/ma071362v

27. Leung, P. S. W.; Teng, Y.; Toy, P. H. Synlett 2010, 1997-2001. doi:10.1055/s-0030-1258130

28. Leung, P. S. W.; Teng, Y.; Toy, P. H. Org. Lett. 2010, 12, 4996-4999. doi:10.1021/ol1021614

29. Teng, Y.; Lu, J.; Toy, P. H. Chem.-Asian J. 2012, 7, 351-359. doi:10.1002/asia.201100721

30. Teng, Y.; Toy, P. H. Synlett 2011, 551-554. doi:10.1055/s-0030-1259515

31. Lu, J.; Toy, P. H. Synlett 2011, 659-662. doi:10.1055/s-0030-1259690

32. Diebold, C.; Becht, J.-M.; Lu, J.; Toy, P. H.; Le Drian, C. Eur. J. Org. Chem. 2012, 893-896. doi:10.1002/ejoc.201101075

33. Yang, Y.-C.; Leung, D. Y. C.; Toy, P. H. Synlett 2013, 1870-1874. doi:10.1055/s-0033-1338963

34. Kumar, M.; Pandey, S. K.; Gandhi, S.; Singh, V. K. Tetrahedron Lett. 2009, 50, 363-365. doi:10.1016/j.tetlet.2008.11.009

35. Kwong, C. K.-W.; Huang, R.; Zhang, M.; Shi, M.; Toy, P. H. Chem.-Eur. J. 2007, 13, 2369-2376. doi:10.1002/chem.200601197

36. Kwong, C. K.-W.; Fu, M. Y.; Law, H. C.-H.; Toy, P. H. Synlett 2010, 2617-2620. doi:10.1055/s-0030-1258576

37. Lu, J.; Toy, P. H. Synlett 2011, 1723-1726. doi:10.1055/s-0030-1260808

38. Lu, J.; Toy, P. H. Synlett 2011, 2985-2990. doi:10.1055/s-0031-1289900

39. Sugiura, M.; Sato, N.; Kotani, S.; Nakajima, M. Chem. Commun. 2008, 4309-4311. doi:10.1039/B807529H

40. Sugiura, M.; Sato, N.; Sonoda, Y.; Kotani, S.; Nakajima, M. Chem.-Asian J. 2010, 5, 478-481. doi:10.1002/asia.200900450

41. Cao, J.-J.; Zhou, F.; Zhou, J. Angew. Chem., Int. Ed. 2010, 49, 4976-4980. doi:10.1002/anie.201000896

42. Chen, L.; Shi, T.-D.; Zhou, J. Chem.-Asian J. 2013, 8, 556-559. doi:10.1002/asia.201201130

43. Lu, J.; Toy, P. H. Chem.-Asian J. 2011, 6, 2251-2254. doi:10.1002/asia.201100296

44. Tang, X.; An, J.; Denton, R. M. Tetrahedron Lett. 2014, 55, 799-802. doi:10.1016/j.tetlet.2013.11.098

\section{License and Terms}

This is an Open Access article under the terms of the Creative Commons Attribution License (http://creativecommons.org/licenses/by/2.0), which permits unrestricted use, distribution, and reproduction in any medium, provided the original work is properly cited.

The license is subject to the Beilstein Journal of Organic Chemistry terms and conditions: (http://www.beilstein-journals.org/bjoc)

The definitive version of this article is the electronic one which can be found at: doi: $10.3762 /$ bjoc. 10.143 